\title{
The Centre Mersenne, one year of operation
}

\author{
Thierry Bouche, Evelyne Miot and Célia Vaudaine
}

\section{Introduction}

1 The Centre Mersenne for Open Scientific Publishing, ${ }^{1}$ developed by Mathdoc, ${ }^{2}$ opened to the public on 1st January 2018 (Bouche et al. 2018) as a diamond open access publishing platform for scientific publications written in LaTeX. ${ }^{3}$ As such, it provides a wide range of technical and editorial services for the community to help editorial teams efficiently run their journals in a dedicated environment.

2 The project was initiated with the objective of creating a case model for open access well done, in an efficient, transparent, and responsible way to address the demand within the scientific community for open, community-led and free publication solutions.

3 During the first year of operation, one main goal has been pursued: to open the platform and successfully publish the first journals. On one hand, Centre Mersenne inherited 9 mathematics journals and 7 proceedings from the Cedram ${ }^{4}$ and started to migrate them. On the other hand, three newly-created journals were already in the process of joining the project.

4 Secondary objectives were to raise awareness and gain legitimacy about this new infrastructure among the scientific communities and to make a compelling case for journals to flip to open access and join us.

5 The aim of this paper is to take stock and give a progress report of this first year of operation. We will first give some background elements about the Centre Mersenne' origins and context. Then we will describe the 2018 actions and activities (communication actions, journal accessions...), and provide feedback on our journals, services and economic model. Lastly, we will focus on the first journals joining the Centre Mersenne. 


\section{Background}

\section{Background elements}

\section{Introducing the Centre Mersenne}

6 The Centre Mersenne for open scientific publishing is an open access publishing infrastructure for scientific publications written in LaTeX and agreeing with the diamond OA model (free to publish, free to read), launched in January 2018.

Public funding from UGA and CNRS made it possible, with additional initial support by Grenoble IDEX (a French excellence initiative).

8 The characteristics of Centre Mersenne are the following: documents all written in LaTeX (that mainly covers so-called 'math and other sciences' sciences but not only), a multidisciplinary openness, and a wide range of services that you could find in any traditional scientific publisher. Centre Mersenne provides:

- editorial services (typesetting, copy-editing), software tools (a platform, OJS instances) and technical tools and services (websites, help for indexation, matching...)

- mutualised services (managing editor) and expertise to the editorial teams who wish to create a new journal, to flip their journal or to improve their production flow.

- a scalable and sustainable publication platform where articles and metadata are freely available, without any financial, technical or legal conditions.

Figure 1: Front Page of the Centre Mersenne
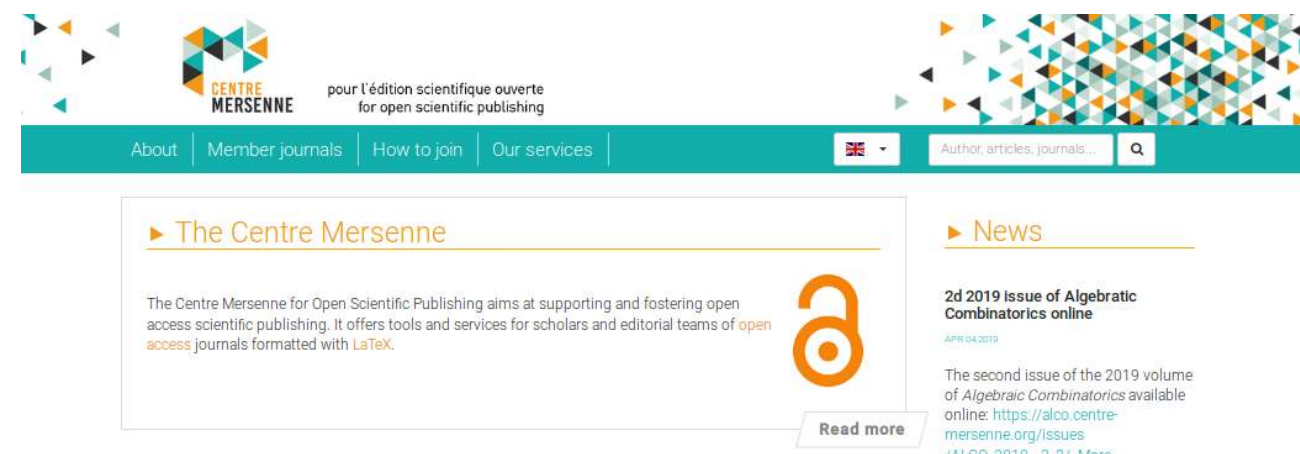

- Our journals

News

2d 2019 Issue of Algebratic

Combinatorics online

The second issue of the 2019 volum of Algebraic Combinatorics available of Algebraic Combinatorics
online: hitps://alco.centre-
mersenne org/issues

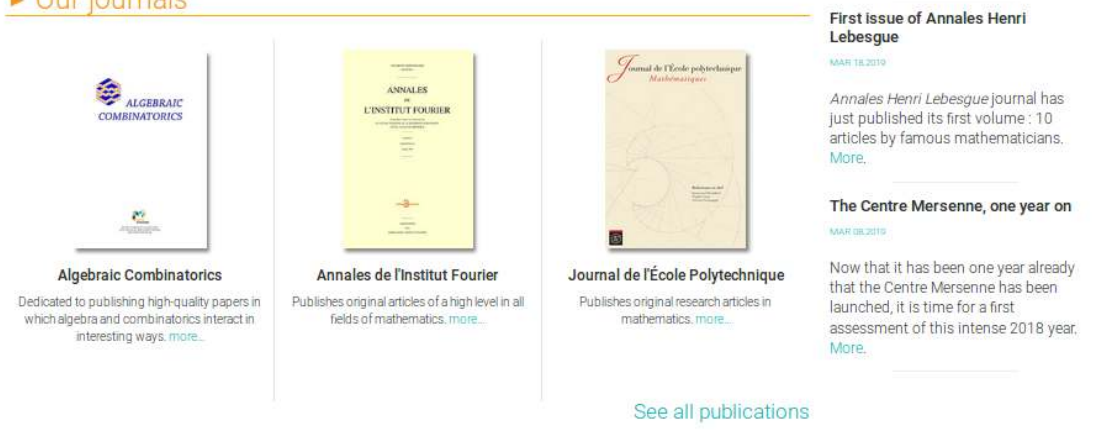




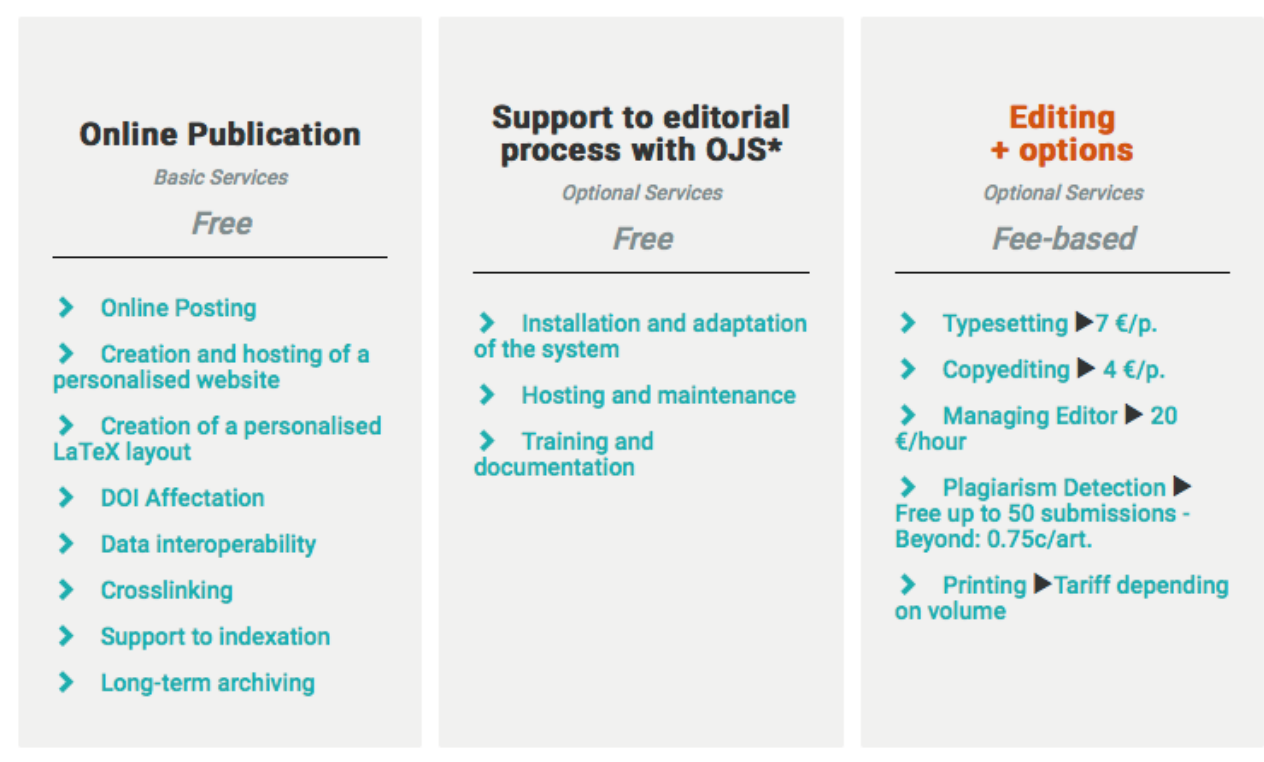

\section{Reminder of the Centre Mersenne goals}

9 The creation of the Centre Mersenne is the result of a strong and firm will by French public Academic institutions to take part in the renewal of the free editorial offer, to contribute to bibliodiversity, and to challenge the increasing privatisation of research outputs.

2018 saw major changes in the open access publishing environment. Numerous initiatives were launched (mandates, policies, plans like Plan S, projects like Jussieu Call) with the purpose of accelerating the transition to full and immediate Open Access and convergeing towards a more open publishing environment, scientific independence, open and free access...

11 Made by researchers for researchers, the Centre Mersenne has been built as a not-forprofit, academic-led, full-featured publishing alternative to for-profit publishing meant for scholars to regain control over the publishing process. It will welcome either newlycreated journals or journals converting to open access.

\section{Reminder of the origins of the Centre Mersenne}

The Centre Mersenne didn't start from scratch. It is developed by Mathdoc, a joint service unit of Université Grenoble Alpes (UGA) and the Centre national de la recherche scientifique (CNRS), ${ }^{5}$ based in Grenoble (France) which benefits from the strong support (human and financial means) of Institut national des sciences mathématiques et de leurs interactions (INSMI) ${ }^{6}$ of the CNRS.

Mathdoc has been around for nearly 25 years. Its core mission is to develop documentrelated services for librarians and researchers in mathematics. Its first action with a webpublishing facet was the Numdam digital library launched at the beginning of this century which is now used daily by mathematicians worldwide. In 2005, Mathdoc launched a publishing platform for academic math journals named Cedram. Ten years later, all hosted journals had moved to Open access and it was felt that time was ripe for a 
whole rethinking of this activity. The decision has been taken to enlarge the number of editorial services and to widen the scientific domains to support diamond $\mathrm{OA}$ for a wider range of publications. This is how the Centre Mersenne came into being. The concrete work started in 2017, thanks to generous funding from Grenoble IDEX (ANR grand 15IDEX-0002).

The preparatory work covered the creation of a new platform for hosting and disseminating scholarly publications (derived from the new Numdam platform launched in 2017), learning how to install and customize PKP's Open Journal System ${ }^{7}$ (OJS), defining the legal framework and preparing a catalog of services. Cedram is scheduled to disappear this year 2019, and to be integrated in the math journals corpus of the Centre Mersenne. A short description of the Centre Mersenne is to be found in Bouche et al. (2018).

\section{Reminder of the organisation of the Centre Mersenne}

15 A team of 12 persons, shared with other Mathdoc projects, working full time or part time (total of 6,25 full time equivalent dedicated to the Centre) mainly composed of IT developers.

Table 1: Number of staff

\begin{tabular}{|c|l|l|}
\hline Job function & Number of staff & Full time equivalent \\
\hline $\begin{array}{c}\text { IT developers } \\
\text { - Platform development and maintenance } \\
\text { - OJS development and maintenance } \\
\text { - Web development }\end{array}$ & 4 & $\begin{array}{l}3,25 \\
0,75 \\
1,5\end{array}$ \\
\hline $\begin{array}{c}\text { Editing* } \\
\text { - LaTeX layout and typesetting* }\end{array}$ & 1 & 1 \\
\hline Coordination and administrative work & 2 & 1 \\
\hline System and Network Administrator & 1 & 1,1 \\
\hline Leadership & 2 & 0,3 \\
\hline
\end{tabular}

* The Editing team is reinforced by 2 freelances: one layout editor working for us on a regular basis $($ FTE 0,2$)$ and one copyeditor, working upon request.

Two governance bodies: a Scientific Council (composed of scientists), assisted by a pool of experts (representative of disciplines that are not represented in the scientific council), and a Steering Committee (composed of representative of our supporting institutions).

\section{Reminder of the business model of the Centre Mersenne}

The Centre Mersenne follows a Diamond Open Access economic model mostly based on public funding, which allows us to provide free services, but also relying on journals contributions for some services (Editing, Add-ons). 
Our economic model was built up considering our resources, that come from our supporting institutions (CNRS and Université Grenoble Alpes) and IDEX which fund three positions for a three-year period.

Our costs structure is divided into four items: infrastructure development and maintenance, training of editorial teams and staff, coordination and initial set-up, and running costs depending on each journal's workflow.

Free core services: With the amount of funding we get, we can cover the following costs: infrastructure development and maintenance, training of editorial teams and staff, coordination and initial set-up, which allows us to deliver the Publication and OJS services for free. Even some marginal costs (such as DOI attribution costs, various subscriptions...) are borne by Centre Mersenne and are not passed on to the journals.

These costs are not passed on to the journals.

As most of our services are developed internally, staff costs represent the great majority of our budget. Overheads are marginal and shared with other Mathdoc's projects.

Journals contribution for optional services: Regarding the journals running costs, they correspond to optional services such as typesetting, copyediting, plagiarism detection. Those services are outsourced by Centre Mersenne and depend on each journal's activity. Costs are thus variable and can't be supported by Centre Mersenne but are passed on to the journals. Journals have then to find funding sources. The fees are fixed at cost price which means that we reflect the exact price we pay for the services.

4 Journals can still join Centre Mersenne without selecting those fee-based services.

Example of Typesetting: Before the openning of the Centre Mersenne, the only charged service delivered by Cedram was the Typesetting service. 6 Cedram journals benefited from it and were (and still are) financially supported by the CNRS (via INSMI) which supplied Cedram with one in-house staff (belonging to the CNRS) dedicated to typesetting. In average, a full-time typesetter can process 6000 pages per year.

26 For other journals, the typesetting service is outsourced to two qualified subcontractors. Others are being investigated as the volume is steadily growing.

7 For Centre Mersenne to be able to provide free services sustainably in the medium term, we can integrate three to four new journals maximum a year (corresponding to 1000 new pages a year).

\section{One year in review}

28 The Centre Mersenne opened in January 2018 with a link to Cedram journals as sole content.

The first Centre Mersenne journal, Algebraic Combinatorics, was launched at the end of January 2018, hence officially inaugurating the real start of our platform.

At the beginning of 2019, the Centre Mersenne was hosting 5 journals and relayed the whole Cedram content ( 7 journals, 6 proceedings and 1 book.) 
Table 2: Results as of 2019

\begin{tabular}{|c|c|}
\hline $\begin{array}{l}\text { Number of pages published online, including Cedram } \\
\text { publications }\end{array}$ & 7011 \\
\hline $\begin{array}{l}\text { Number of articles published online, including Cedram } \\
\text { publications }\end{array}$ & 206 \\
\hline Number of pages typeset & $\begin{array}{l}5612 \\
\left(\begin{array}{l}5229 \\
\text { outsourced })\end{array}\right.\end{array}$ \\
\hline Number of websites creation & 5 \\
\hline Number of OJS instances adaptations & 4 \\
\hline Number of LaTeX layout creations & 3 \\
\hline
\end{tabular}

\section{Communicating around the project}

31 While active, our communication strategy remained intentionally modest. Our priority being to ensure that each new journal, in particular the first ones joining us, would be integrated in the best possible conditions.

The project was actively introduced by the team and particularly by the scientific council members in international events (mathematics conferences, scholarly publishing and open access oriented) but also through the publication of articles. The launch of Algebraic Combinatorics (see below), much talked about in the scientific community, did also a lot to promote the Centre Mersenne.

\section{Journals joining Mersenne: accessions and migrations}

\section{First demands and accessions}

Throughout 2017 and 2018, the Centre Mersenne received many information requests not always followed-up, and also a few demands that could not be addressed: non-scholarly journals out of Mersenne's scope, commercially owned non-OA journals seeking cheap IT support... But this confirms a real need from the scientific community for a publishing structure like Centre Mersenne and for certain services.

Three of them were approved to join: Algebraic Combinatorics (mathematics), Annales Henri Lebesgue (mathematics) and Open Geomechanics (geomechanics).

\section{First migrations of Cedram journals}

All Cedram journals are expected to migrate to the Centre Mersenne by the end of 2019 and the migration process started with two journals: Annales de l'institut Fourier and Journal de l'École polytechnique. Both are now fully members of Centre Mersenne and using its services. 
36 Migrating Cedram journals to the Centre Mersenne technically means creating a new website within the new platform, enhancing the information and clarifying the policies (explicit choice of license, compliance with good practices...) and setting-up new services they could benefit from that Cedram didn't provide. But the overall organization remains the same, as is the team they are in relation with.

\section{Mersenne 2018 services delivery}

\section{Overview of the services to journals and seminars}

37 Here is an overview of the services delivered by Centre Mersenne to journals and seminars (including Cedram's) in 2018.

Table 3: Services delivered in 2018

\begin{tabular}{|l|l|l|l|l|l|}
\hline & Publication & OJS & Typesetting & Copyediting & Plagiarism \\
\hline Journals & 12 & 6 & $\begin{array}{l}8 \\
6 \text { for INSMI journals }\end{array}$ & & 2 \\
\hline Seminars & 6 & & 2 & & \\
\hline
\end{tabular}

\section{Publication service}

About publication service: All journals automatically benefit from the Publication services, including the following sub-services : DOI registration, indexing support, long-term archiving and delivery of metadata through dedicated OAI-PMH servers, but also creation and implementation of a LaTeX layout and design of a website (all websites comply with fair principles of ethics and transparency, and follow industry best practices (such as those of OASPA, ${ }^{8}$ DOAJ, ${ }^{9}$ COPE, ${ }^{10}$ as well as learned societies).

Articles are published, through journals websites, on our platform and available for free to read and download. 
Figure 3: Articles as published on the Centre Mersenne website

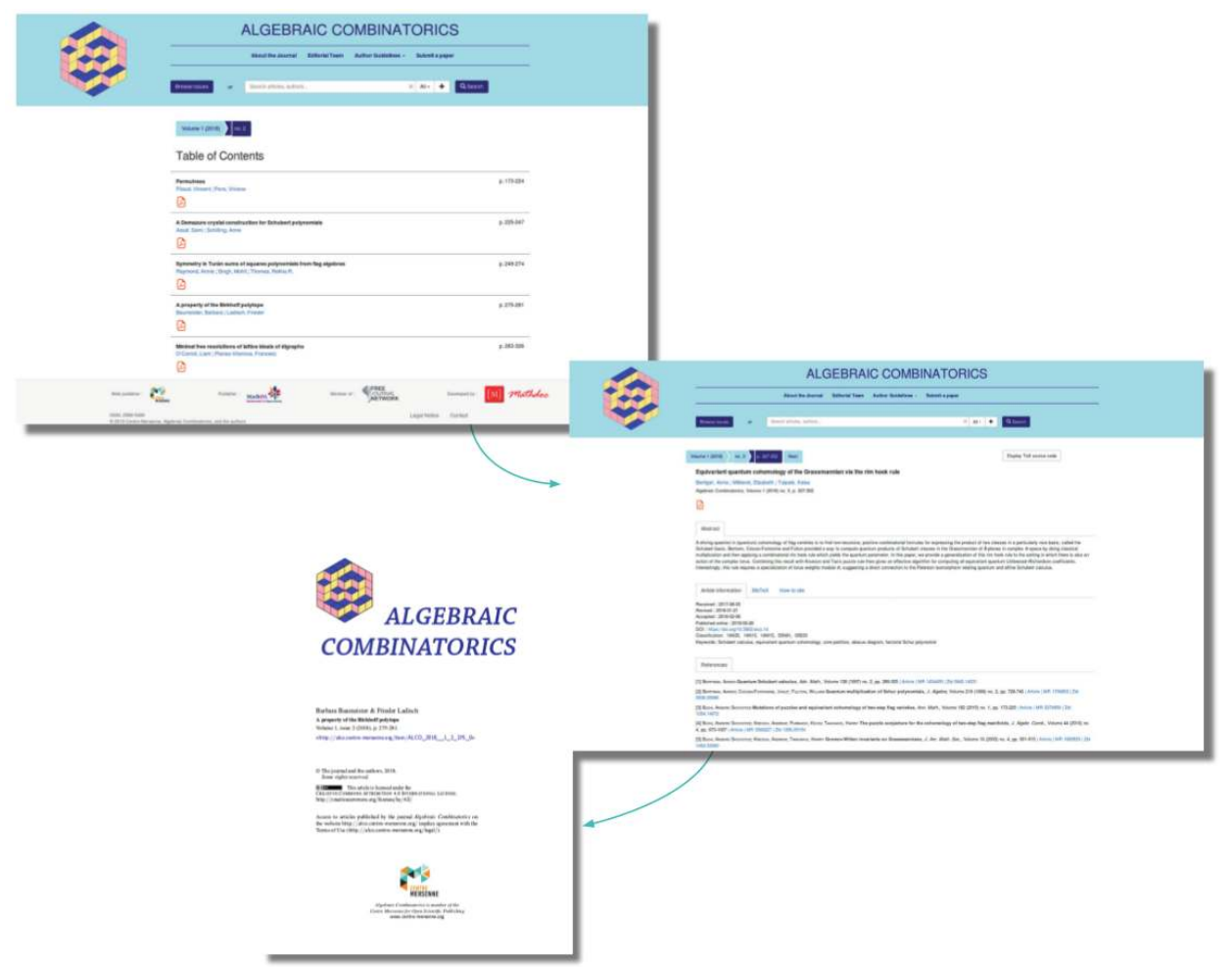

About publication 2018 activity: In 2018, we published online 206 articles (7011 pages), counting Cedram journals. The Mersenne platform posted only 28 articles (722 pages).

41 Five new responsive websites were created with each journal's visual identity as well as three original LaTeX layouts.

New functionalities were also implemented during the year to address the journals' needs and to improve accessibility (introductory videos attached to articles, supplementary material, datasets, possibility to propose TeX sources as an alternative dissemination format fit for the visually impaired...) 
Figure 4: Journals on the Centre Mersenne website

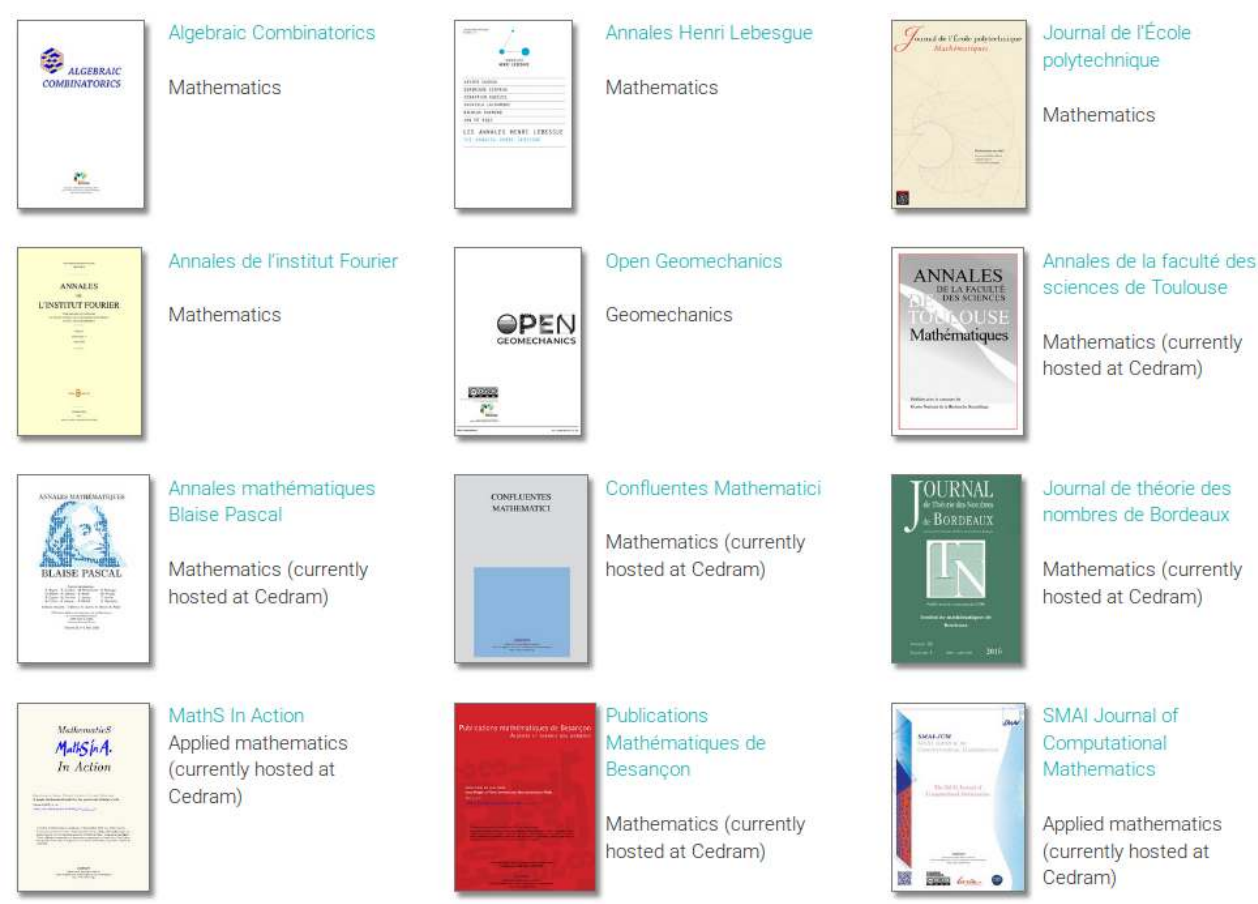

\section{Support to editorial process with OJS service}

A Support to editorial process: The OJS service represents a large part of the Centre Mersenne activity. This tool's purpose is to make the journal management much easier for the editorial teams. To be effective, it has to be adapted to each journal selection workflow.

Support to editorial process 2018 activity: During 2018, three new OJS instances were installed and adapted to each journal's specific workflow. Some required the development of new plug-ins and add-ons. The Centre Mersenne team also did a lot of hard work training the editorial teams to help them become more familiar with the tool.

Figure 5: The three dashboards

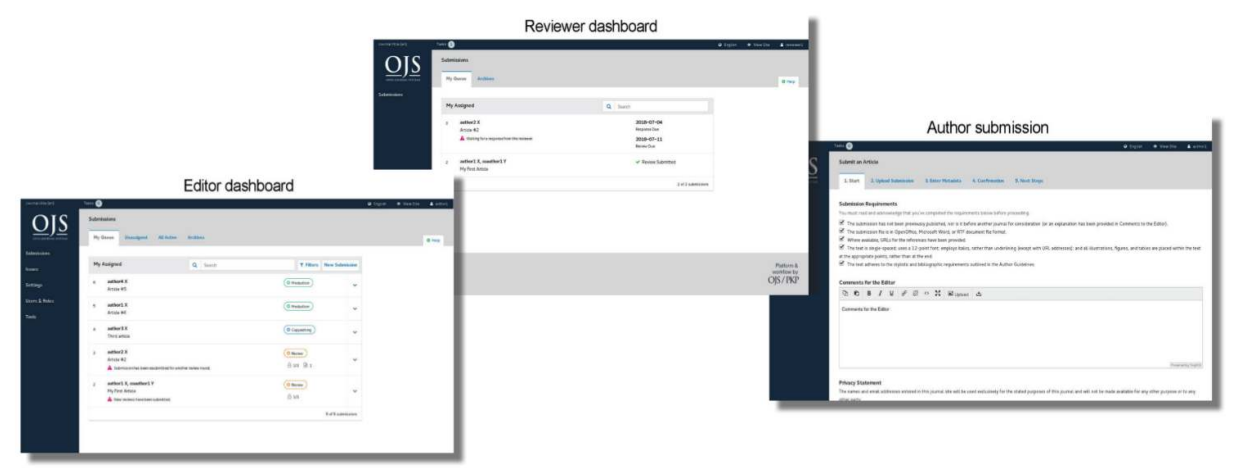




\section{Typesetting service}

About typesetting: For editorial teams, this is a very time consuming and complex task because articles contain a mixture of text (where typographic rules, and grammatical rules, apply), together with tables, figures, equations, etc.

Figure 6: From TeX + bibTeX to PDF

Fichier tex

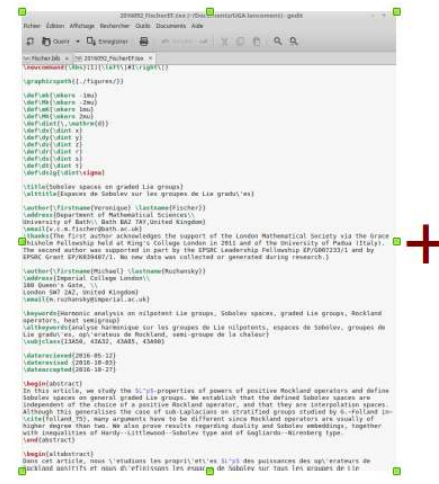

Fichier bibtex

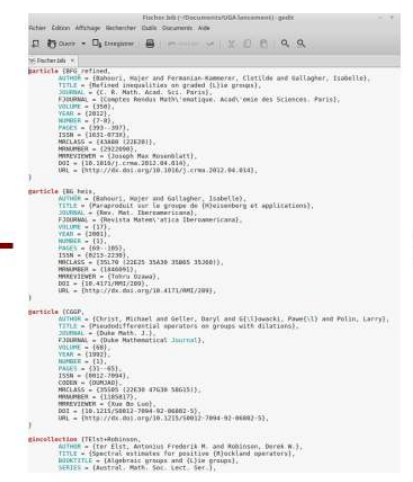

\section{Fichier pdf final}

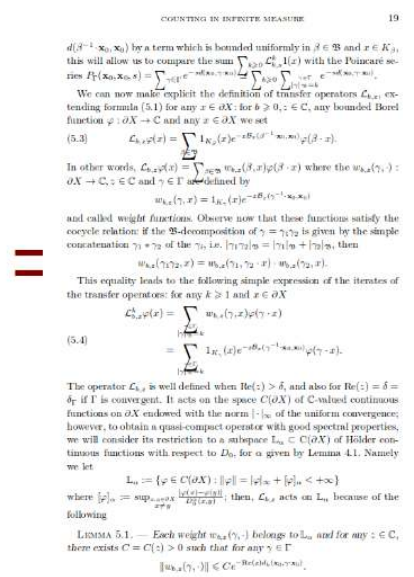

These being sometimes very difficult to insert into the page format or be consistent with the overall layout of the journal. Also, there is more to it at Centre Mersenne than just page make up, as we have to clean up author's LaTeX code in order to remove all that could choke with the journal's style, and to prepare the electronic edition which is entirely controlled by the LaTeX sources. It means for instance that all metadata (including bibliographic references, usually structured with bibtex) have to convert smoothly to XML with formulas in MathML (Bouche 2006; Bouche 2008).

About typesetting 2018 activity: In 2018, 5612 pages were typeset at Centre Mersenne, using our LaTeX/XML production system (directly inherited from Cedram), with a specific set of standard (page make up, typographic rules, etc.) for each publication.

The remaining 1399 pages, not typeset at Centre Mersenne, were processed by journals themselves, using our system and following our standards. In many cases, it is a colleague who takes care of this, but it can also be staff at a lab involved with the journal, or hired on purpose.

\section{Additional support services}

Demands also concerned other tasks such as support on legal and administrative issues (advice on licenses and copyright, editorial workflows, legalities, process of journal creation...). New editorial teams have usually no experience in the matter of creating a journal and such tasks can be very time-consuming. We decided, with the help of our supporting institutions (UGA and CNRS), to support journals in their process. 


\section{Feedbacks on this first year of operation}

\section{About the Centre Mersenne reputation and legitimacy}

A lot of interest...: our project has aroused a real interest in the community in a favourable international context. We were approached by several open access partners/actors: Free Journal Network, Scholastica to participate in international events... Articles were published in various publications mentioning Centre Mersenne.

51 And our multidisciplinary approach is confirmed. While requests are mostly from mathematics projects, and the infrastructure is still better known in the mathematics community, we already started to reach other scientific communities. We indeed welcomed our first non-mathematics journal and start to receive applications for a variety of scientific disciplines.

A few accession requests: taking off-topic demands apart, the number of requests submitted remains low. One reason could be the modest amount of advertising on our part. Other reasons could be that setting up a journal takes time and requires a good deal of prior thinking. There may be long delays between first contacts with a journal-to-be and the reception of its accession request.

53 The community may also be timid with new structures and would rather wait to see what happens.

\section{About the requests for services}

54 A need for journal management solutions: the Open Journal System generates a great interest among most editorial teams, who are in need for easy-to-learn and open source solutions to help them manage their journal. OJS happens to be a good option but still requires assistance to make full use of its potential.

The pursuit of editorial quality: typesetting is one of the most popular services, which reveals the needs for editorial quality and efficient tools to run their journals.

\section{About the journals characteristics}

Mostly newly-created journals... A great majority of the accession demands are made by journals in the process of being created.

Only one was a flipping journal, i.e. an editorial board leaving a commercial publisher in order to set up a non-profit OA journal. The need for help in the process of journal creation and in administrative procedures is significant.

The legal publisher matters... For editorial boards which are not backed up by an institution, the question of finding a legal publisher often arises. Most of the journals have an international scope and are reluctant to go for locally anchored entities (e.g. universities). Learned societies, foundations, or national institutions are good solutions, though.

The funding sustainability issue... Journals requesting fee-based services (typesetting, e.g.) need to find funding to cover the costs. Funds can be allocated by universities, foundations, academic libraries, institutions... but are usually non-recurring measures or given for short periods, which may lead to sustainability issues. 


\section{About the Centre Mersenne business model}

\section{university library, aimed at sustaining open access initiatives. Such funds will be used to} support the Centre's operation, thus to reduce operating costs requested.

Additional resources received in 2018:

- Donation: $3000 €$

\section{Focus on journals}

The creation of Cedram, encouraged by INSMI, aimed at technically supporting mathematics journals with a publication platform and editorial services. All of Cedram journals are migrating to Centre Mersenne and will continue benefiting from the same services they used to.

\section{Cedram journals: Annales de l'institut Fourier}

The electronic version of Annales de l'institut Fourier, ${ }^{11}$ has been web-published by Cedram since 2005, benefiting from the following services: Publication, Typesetting and Support to editorial process. Their migration process to Centre Mersenne started in 2018.

- Theme: Mathematics

- Legal Publisher: Association des Annales de l'Institut Fourier

- In Cedram since 2015/ Centre Mersenne since 2018

- Open access since 2015 
- Publication volume: 2700 pages/year - 75 articles/year

- Services: Publication, Support to editorial process, typesetting

- Funding sources: CNRS

\section{Journal background}

67 Annales de l'institut Fourier (AIF) is owned by an independent association (Association des Annales de l'institut Fourier) and supported by the Institut Fourier (a math lab in Grenoble). It was created in 1949. It got a relatively amateur electronic edition around year 2000. Backfiles were digitised and posted online (with a 5 year moving wall) at Numdam. The journal was a founding member of Cedram in 2005. At that time, it was mainly a paper subscription based journal, with a bonus electronic edition reserved to subscribers (during five years). The journal switched to open access in 2015, with a strong impetus coming from INSMI, that decided to cover the typesetting costs to facilitate the move (Rolland and Vanel 2016). Annales de l'institut Fourier has currently the highest publication volume of Cedram journals with around 2700 pages and 75 articles published a year (out of $300+$ submissions).

\section{Services provided by the Centre Mersenne}

- Publication: Centre Mersenne delivered a whole new website with their new visual identity. The new website was launched in January 2019.

- Support to editorial process service: a comprehensive OJS instance was developed for the Annales de l'institut Fourier which was so far using another journal management system (Ruche, partially developed at Mathdoc, but it never took off and is not maintained anymore). It took a lot of work from the Centre Mersenne team to adapt the system to the collective decision-making process that OJS did not natively support. The Centre Mersenne IT team developed specific plug-ins and add-ons so that each editor can participate in the decisions.

70 - Typesetting service: all of the journal's articles are typeset by our in-house staff, costs being thus borne by INSMI.

\section{Cedram journals: Journal de l'École polytechnique}

71 The Journal de l'École polytechnique ${ }^{12}$ (JEP) had been web-published by Cedram since 2014 and was migrated to Centre Mersenne at the end of 2018. They benefit from Publication and Support to Editorial Process services.

- Theme: Mathematics

- Legal Publisher: Ecole Polytechnique, Paris

- Creation date / In Centre Mersenne since: 2014

- Natively open access

- Publication volume: 950 pages/year-24 articles/year

- Services: Publication, Support to editorial process, typesetting

- Funding sources: INSMI 


\section{Journal background}

The Journal de l'École polytechnique was a generalist scientific journal published by École polytechnique between 1795 and 1939. After some 50 years, a small group of mathematicians decided to revive the journal as a generalist mathematics journal with an open access electronic version web-published by Cedram. A small number of annual volumes is printed a posteriori and sold to a few libraries, mostly for the sake of longterm preservation. The first issue came out in 2014, 91 articles have been published since. The journal already established a very good reputation (Sabbah 2014).

\section{Services provided by the Centre Mersenne}

73 A new website has been created on the Centre Mersenne's platform and launched early 2019.

74 As for Support to Editorial Support, the changeover from Cedram to Centre Mersenne was an opportunity to upgrade OJS from version 2 to 3 . The Centre Mersenne team is currently working on specific adaptations for the journal.

\section{Algebraic Combinatorics, an example of a flipping journal}

Algebraic Combinatorics ${ }^{13}$ was the first member of Centre Mersenne. Its first issue was published in January 2018, soon after the Centre's launch.

- Theme: Mathematics

- Legal Publisher: MathOA (Dutch foundation)

- Creation date / In Centre Mersenne since 2018

- Natively open access

- Publication volume: 722 pages/year-28 articles/year-Expecting around 1000 pages in 2019

- Services: Publication, Support to editorial process, typesetting

- Funding sources: $\mathrm{RNBM}^{14}$, Foundation Compositio Mathematica

\section{Journal background}

Algebraic Combinatorics (ALCO) is a newly-created journal in mathematics, academy- led, and following Fair open access principles. It is published by the MathOA Foundation. The context in which it was created makes it a successful example of a flipping journal and illustrates the trend in the scientific community to regain control of the publishing process (Wilson 2018; Wilson et al. 2018). The journal was created in July 2017 after the editorial board of the Journal of Algebraic Combinatorics (JACO), published and owned by Springer, resigned in June 2017. They were strongly backed by the MathOA Foundation during the whole flipping process. First contacts with the Centre Mersenne were made through MathOA during that period, and the decision to support the flip was rapidly reached. 


\section{Services provided by the Centre Mersenne}

When MathOA contacted the Centre Mersenne, in June 2017, the Algebraic Combinatorics journal was not yet created. Their demand concerned the following services: Publication, Support to editorial process, Typesetting and plagiarism detection, but also help in the creation process, weighing that they expected the first issue to be launched in a sixmonth time. A very short period to set up a whole new journal during which they built up a new team of editors. And during which the Centre Mersenne, still a work in progress at that time, finished building the platform and helped them on administrative and organizational matters, with guidance from the CNRS and UGA.

- Publication: Centre Mersenne and Algebraic Combinatorics' websites were set up simultaneously to be ready by the end of 2018. Centre Mersenne helped on the presentation and information mentions (such as Copyright notice, instructions for authors...), and the first issue of Algebraic Combinatorics was released in January 2018.

- Support to Editorial Process: an OJS instance was adapted to the needs of the editorial team regarding the peer review process of the journal. The Centre Mersenne team also liaised extensively with the editors for training and addressing their demands. The submission system was delivered in July 2017 and opened in September 2017.

- Typesetting: because of uncertainty over available funding, typesetting was carried out by a colleague during the first months. But the journal eventually secured financial support (Foundation Compositio Mathematica and RNBM, the French math libraries network) with the help of MathOA and each article is now systematically passed on to us. Centre Mersenne processed around 500 pages in 2018 for Algebraic Combinatorics.

\section{8 year in review}

In a six month period, the editorial team succeeded in gathering enough high quality articles for a launch. In 2018, 5 issues (28 articles, 722 pages) were published.

The journal rapidly gained a legitimacy of its own since they received in 2018 the same amount of submissions as JACO had (Thomas 2048). They are already indexed in two of the most important mathematics indexing databases zbMath and MathSciNet.

Contrary to the expectations of some of the ALCO editors, Springer kept the Journal of Algebraic Combinatorics alive with a new editorial board. It remains to be seen whether this creates an interesting competition, the journals specializing somehow, or whether one of them will vanish eventually. During 2018, the volume of submissions and the number of accepted papers has been growing rapidly, pointing towards JACO's rates before the flip in a few years.

\section{Annales Henri Lebesgue, a new mathematics journal}

The Annales Henri Lebesgue's $\mathrm{s}^{15}$ team first contacted the Centre Mersenne in May 2017 and joined in 2018. Its first issue was published in March 2019.

- Theme: Mathematics

- Legal Publisher: ENS Rennes

- Creation date / In Centre Mersenne since 2018

- Natively open access 
- Publication volume: 332 pages/year - 10 articles/year - Expecting around more pages in 2019

- Services: Publication, typesetting

- Funding sources: Scholar libraries

\section{Journal background} could not take care of themselves: Typesetting and Copy editing services. They are very independent in their journal management in terms of journal creation process, design, website and LaTeX layout creation. They set up and customized their OJS instance themselves, which also serves as the journal's informative website.It opened for submissions in March 2018.

- Publication: the whole publication services were provided apart from the website and the LaTeX layout.

Centre Mersenne developed a sister website to theirs, mimicking the (unusual) presentation to the extent that the 'Contents' part of the AHL website, which is run on our platform, appears as fully integrated in the journal's website (which is based on OJS and hosted in Rennes).

- Typesetting \& copy editing: The estimated publication volume is around 350 pages a year, to be typeset and, for some of them, copy-edited according to specific standards.

\section{8 year in review}

The project started to be advertised in March 2018. The journal rapidly gained international legitimacy and published its first volume in 2019 with 10 articles (332 pages) accepted in 2018 and signed by internationally renowned mathematicians. 


\section{Open Geomechanics: a new geomechanics journal}

- Theme: Geomechanics

- Legal Publisher: ALERT Association

- Creation date / In Centre Mersenne since 2018

- Natively open access

- Publication volume: expecting 100 pages/year - 6 article/year

- Services: Publication, Support to Editorial Process

- Funding sources:

\section{Journal background}

Open Geomechanics ${ }^{16}$ is a newly created journal in geomechanics peer reviewed, non-profit, open-access journal in geomechanics run by researchers. It is the first non-mathematics discipline to join the Centre Mersenne and was initiated by a handful of researchers from all over the world. Their legal publisher is a European geomechanics association (ALERT).

The editorial team was looking for an open access publication platform and contacted the Centre Mersenne after reading an article about Algebraic Combinatorics launch. The managing editors intend to take care themselves of most of the work, including typesetting, so they did not look for financial support.

There aren't yet many open access journals in this scientific area and that's what makes of this journal a precursory and challenging project.

\section{Services provided by the centre Mersenne}

Open Geomechanics demand concerned free services only: Publication and Support to Editorial Process. Typesetting would be carried out by the journal's publisher.

Centre Mersenne supported them throughout the journal creation process, helped defining their strategy and OJS process.

- Publication: Centre Mersenne developed a personalized LaTeX layout and a website that opened in December 2018.

- Support to editorial process: an OJS instance was set up with classic adaptations and was opened to submissions in October 2019. In this scientific area, articles often come with supplementary material. The Centre Mersenne team had to adapt the platform to include information coming from data repositories such as Zenodo...

\section{8 year in review}

Open Geomechanics has not yet started publishing but is gathering submissions. The website opened in January 2019 with a short editorial as first publication.

\section{Conclusion}

For its first year of existence, Centre Mersenne activity has been focused on launching rapidly those journals that were already members in early 2018 on one hand, while migrating all Cedram publications on the other hand. This is still a work-in progress, 
expected to be completed by the end of year 2019. This is our main priority as we showcase our skills while we aim at clarifying our publishing services by merging Cedram into Centre Mersenne.

These last few months have brought up a few new accession requests, some of them from journals with a high publication volume and demands for innovative features. That raises the question of a sustainable growth of our team, resources, and services. We are confident that we can cope in the mid-term, and help more quality journals to embrace the virtues of diamond open access in a responsible way.

\section{BIBLIOGRAPHY}

\section{References}

Bouche, T., E. Miot, C. Vaudaine. 2018. "The Launch of Centre Mersenne, a Technical Infrastructure to Support the Move Towards Diamond Open Access." In Connecting the Knowledge Commons: From Projects to Sustainable Infrastructure. Proceedings of the 22nd edition of the International Conference in Electronic Publishing (ELPUB), June 22-24 2018. Edited by Leslie Chan and Pierre Mounier Toronto: episciences proceedings.

Bouche, T. 2006. “A pdfLaTeX-based automated journal production system.” TUGboat 27:45-50. https://tug.org/TUGboat/tb27-1/tb86bouche.pdf

Bouche, T. 2008. “CEDRICS: When CEDRAM meets Tralics." In Towards Digital Mathematics Library, proceedings of the DML 2008 workshop, Birmingham, UK, July 27th. Edited by Petr Sojka. Masaryk.

Caruso, X.; D. Cerveau, S. Gouëzel, X. Lachambre, N. Raymond, and S. Vu Ngoc. 2018. "Annales Henri Lebesgue." EMS Newsletter 107 (March): 6-8. https://www.ems-ph.org/journals/ show_abstract.php?issn=1027-488X\&vol=3\&iss=107\&rank=2

Coalition S. "Making full and immediate Open Access a reality." https://www.coalition-s.org/wpcontent/uploads/271118_cOAlitions_Guidance.pdf

Raymond, Nicolas. 2018. "Les Annales Henri Lebesgue : création et légitimation d'une revue mathématique en libre accès." Presentation at the Journées Science Ouverte, Universitée d'Angers, December 6. https://webcast.in2p3.fr/video/es-annales-henri-lebesgue-creation-etlegitimation-dune-revue-mathematique-en-libre-acces

Rolland, A., and R. Vanel. 2016. “Coût des publications: propositions concrètes. L'exemple des Annales de l'institut Fourier." La Gazette des mathématiciens 147:14-18. https:// archivesic.ccsd.cnrs.fr/sic_01266379

Sabbah, C. 2014. “The Journal de l'École polytechnique, A Revival.” Notices of the American Mathematical Society 61, no. 8 (September): 904.

Thomas, Hugh, "Webinar on Demand: How to Start or Flip an Open Access Journal - editors and publishers share their stories. Interview with Hugh Thomas, Co Editor-in-Chief of Algebraic 
Combinatorics." Scholastica HQ https://blog.scholasticahq.com/post/webinar-recording-start-flipopen-access-journal/

Wilson, M. 2018. "Free and Fair Open Access Journals: Flipping, Fostering, Founding." Notices of the AMS 65, no. 7 (August): 817-820. http://www.ams.org/journals/notices/201807/rnotip817.pdf

Wilson. M.; H. Van Maldeghem, V. Reiner, C. Athanasiadis, A. Munemasa, and H. Thomas. 2018. “Flipping JACO." EMS Newsletter 109 (September): 38-41. https://www.ems-ph.org/journals/ show_abstract.php?issn=1027-488X\&vol=9\&iss=109\&rank=9

\section{NOTES}

1. Centre Mersenne's website address: https://www.centre-mersenne.org

2. Cellule Mathdoc or Cellule de coordination documentaire nationale pour les mathématiques, develops services towards French librarians and research mathematicians such as Numdam or Cedram. Mathdoc's website address: http://www.mathdoc.fr/

3. LaTeX is a high-quality typesetting system; it includes features designed for the production of technical and scientific documentation. It is very popular in the scientific community because it enables to effectively typeset mathematics formulas.

4. Cedram for Centre de diffusion de revues académiques mathématiques, a dissemination platform for scientific publications. Cedram's website address: http://www.cedram.org/

5. CNRS for Centre National de la Recherche Scientifique - the French National Center for Scientific Research. CNRS' website address: http://www.cnrs.fr/

6. INSMI for Institut national des sciences mathématiques et de leurs interactions - National Institute for Mathematical Sciences and their Interactions - http://en.insmi.math.cnrs.fr/

7. Open Journal System, an open source journal management and publishing software, developed by the Public Knowledge Project. OJS website address: https://pkp.sfu.ca/ojs/.

8. OASPA is a OSAPA (Open Access Scholarly Publishers Association) an association aiming to support and represent the interests of Open Access (OA) journal and book publishers globally in all scientific, technical, and scholarly disciplines. OASPA's website address: https://oaspa.org/. OASPA's criteria are available at: https://oaspa.org/membership/membership-criteria/

9. DOAJ for Directory of Open Access Journals. DOAJ's website address: https://doaj.org/

10. COPE for Committee on Publication Ethics. COPE's website address: https:// publicationethics.org/

11. Annales de l'Institut Fourier's website address: https://aif.centre-mersenne.org/

12. Journal de l'École polytechnique's website address: https://jep.centre-mersenne.org/

13. Algebraic Combinatorics's website address: https://alco.centre-mersenne.org/

14. RNBM for Réseau national des Bibliothèques de Mathématiques - the French National Mathematical Libraries Network. RNBM's website address: https://www.rnbm.org/

15. Annales Henri Lebesgue's website address: https://ahl.centre-mersenne.org/articles/ and https://annales.lebesgue.fr/index.php/AHL/

16. Open Geomechanics' website address: https://opengeomechanics.centre-mersenne.org/ 


\section{ABSTRACT}

The article describes the results of the first year of the Centre Mersenne for Open Scientific Publishing, a diamond open access platform for scientific publications developed by Mathdoc, a joint service unit based in Grenoble (France).

The Centre Mersenne was launched on 1st January 2018 to offer the scientific community a new open access publication solution for journals publishing in LaTeX and thus contributes to bibliodiversity.

This article discusses challenges faced by the Centre Mersenne while implementing concretely its goals, refining its business model, and actions taken to address the needs of new journals.

This article specifically focuses on the three new journals launched during that year, among which two newly-created and one 'flipped' journal, as well as two newly-migrated journals from Cedram, a dissemination platform for mathematics journals bound to disappear.

\section{INDEX}

Keywords: Open access, scientific publication platform, scholarly publishing, open access journals, bibliodiversity

\section{AUTHORS}

\section{THIERRY BOUCHE}

Université Grenoble Alpes

\section{EVELYNE MIOT}

Centre national de la recherche scientifique (CNRS French National Center for Scientific Research)

\section{CÉLIA VAUDAINE}

Université Grenoble Alpes

celia.vaudaine@univ-grenoble-alpes.fr (corresponding author) 